\title{
The vernacular of Tibet, harnessing panoramic sunshine
}

\author{
N. Blossom \& L. Blossom \\ Interdisciplinary Design Institute, Integrated Design Lab, \\ Washington State University, Spokane, Washington, USA
}

\begin{abstract}
This paper reports findings of field research undertaken in collaboration with students and scholars from the Green Architecture Research Center of Xian University of Architecture and Technology. The focus of the project is the potential that exists for exploiting the abundant solar resources of Tibet in the development of modern urban and rural housing types while at the same time honouring the traditional Tibetan house form.

Pioneer work at the GARC in the Zao Yuan Village of China resulted in an adaptation of the regional vernacular that represents modernization at the same time honouring the yaodong (cavelike) house form of the region. Outcomes from this project demonstrate the success of design strategies that increase solar heat collection and promote circulation of heat throughout the dwelling space. What we see as missing from the first studies (particularly in the context of Tibet) is consideration of the impact these types of intervention may have on the use of interior space. Do these interventions alter the original ambiance and day light levels of the traditional single cavernous vaulted interior? For example, the quality of life as affected by daylight levels within the spaces and on traditional routines and objects of daily living, the material culture as it has been passed down from generation to generation. Through daylight level analysis, both qualitative and quantitative, we provide insight to the way daylight levels affect current interior living conditions in Tibet. The findings suggest that further study is merited to mitigate the impact of modern sustainable interventions.
\end{abstract}

Keywords: interior, daylight, culture, vernacular, solar intervention. 


\section{Introduction}

Rapid urban development in China presents both opportunity and challenge for design experts. In response to China's policy of reform and openness to the outside world in the last decades of the twentieth century, changes in both the rural and urban fabric have been outpaced only by accelerated economic growth at the end of the century. The boundaries of cities are expanding as more and more of the population seek prosperity.

In this context, there develops a phenomenon that challenges not only the Chinese but also the entire world population. Rapid industrialization and modernization in response to economic growth threatens the homogenization of the built form in China. Scholars [1-3] have commented on this "happening" as cities throughout the world have undergone similar developments and assumed similar shapes. Whether one is in Shanghai or Dubai, the ubiquitous skyscraper dominates the skyline. Shopping malls, Starbucks, and gated communities demonstrate the potential influence of western suburban socio-culture [4]. Prosperity begets consumerism, bicycles are traded for automobiles, candlelight is traded for light bulbs, and breezes are traded for air conditioning. Health reforms, improved sanitation and urban infrastructures increase life expectancies while simultaneously placing greater strain on the food supply and impacting the environment. As China stands at the precipice of increasing prominence politically and economically in the $21^{\text {st }}$ century, the architectural response to these phenomena has both positive and negative potential. The negative is obvious, that is, the looming threat to the global environment. The positive is more promising; lessons learned elsewhere, both positive and negative, give the Chinese and their partners the perspective to lead the world with a more balanced architectural and ecological response to modernization.

We find one such leader in our colleague, Dr. Liu Jiaping, Professor of Architecture at the Xian University of Architecture and Technology and Director of the university's Green Architecture Research Center. Dr. Liu's work in the Zao Yuan Village is recognized as cutting edge in China, not solely for the outcome but also for the design process used to arrive at the outcome, a modern adaptation of the regional vernacular that on the one hand represents modernization and on the other honours the prevailing historic house form of the region. The premise of Dr. Liu's work is "the combination of traditional vernacular elements with reflective external intervention" [5]. The point being that with sensitive interpretation of local values and studied expert intervention (in this case with an emphasis on sustainability as well as modernization) a successful outcome can serve both the past and the future of rural communities. This approach is consistent with the theories of Frampton, and others who suggest that critical regionalism, that is, professional intervention into vernacular building processes is not a contradiction in terms, but rather a potentially vital tactic for the preservation of cultural memory (and hence regional identity) in newly built environments. Further it combats negative by-products of globalization in the realm of architecture. [6,7] It is GARC's position that there is a natural affinity between Frampton's tenets of critical regionalism and the 
ethic of sustainability that can lead to regional expressions of built form. [8] In fact GARC'S position is consistent with vernacular investigations in other parts of the world. The logic of the approach is clear. Vernacular environments in any setting offer clues on how a building can be integrated with the natural, cultural and environmental values of a region. [9-11] Even in the most basic forms, these building types demonstrate the primary goals of the builders as functionally and environmentally appropriate solutions. Thus the life, climate, topography, locally available materials and traditional building technology can be viewed as the driving forces in these environments. Of interest to this study is how the GARC approach will be implemented in the Tibet Autonomous Region (TAR), looking specifically at natural light as a key factor of both culturally and environmentally responsive design solutions.

\section{Tibet}

The issue of cultural memory in Tibet is too complex for the scope of this paper. However, as in other cultural settings, key components of the house can be identified as representative of a regional Tibetan vernacular. This project looked specifically at urban and rural housing in Lhasa and in adjacent villages. Primarily, the vernacular in this region can be categorized by its urban or rural location. The majority of old houses in Lhasa were destroyed during the second half of the twentieth century as the city came under the control of forces outside Tibet. Thus there is considerable difference between what might be viewed as urban vernacular and rural vernacular. This paper focuses on data from rural vernacular housing types.

Lhasa is considered the political, economic, cultural and religious center of the TAR. It has a history of 1,300 years. Lhasa is situated in the alluvial plain of a valley at 3,650 meters above sea level. The climate belongs to the half drought plateau area. The annual rainfall, which occurs mostly at night, is between $200 \mathrm{~mm}$ and $500 \mathrm{~mm}$, and concentrates from June to September. Strong winds characterize the dry seasons of winter and spring. Temperatures range from 14 to 28 degrees Celsius fluctuating dramatically from day to day. There are only 100 to 120 days without frost annually. Lhasa is the least polluted city in China, surrounded by a region of abundant blue sky, clean water, and fresh air. The sun shines on average 3000 hours annually. It is recognized as a cultural and environmental factor that has influenced vernacular house forms as well as an abundant natural resource.

\section{Vernacular house forms}

Nearly $88 \%$ of the Tibetan population of the TAR is found in the rural areas. Because of the large percentage of population in rural homes, one can posit that the rural house forms are most highly representative of Tibetan tradition both in form and function. Investigation of the characteristics of these rural homes provides the discussion for climatic considerations. 


\subsection{Climatic considerations}

In response to the fluctuating climatic conditions, the house form demonstrates three strategic approaches: orientation, protection and moderation. Two factors strongly influence house orientation, wind and sun. The wind challenges living conditions by exacerbating the extreme daily fluctuation of temperatures as well as promoting desertification during the dry seasons. It comes predominantly from the west, changing on a north-south access. Similarly, the extreme temperature fluctuations are both exacerbated and relieved through orientation to the sun.

By observation of rural Tibetan costume in the month of May, one can quickly see that Tibetans respect the sun's powers. Heads, arms and legs are covered with cloth, protected from the sun even in the warmest hours of the day. Similarly, components of the house form protect humans and animals from sun and other climatic extremes manifested in the wind, dust and snow

The unique circumstance of climate in Tibet demands that the house form respond to extreme swings in temperature in short periods of time. Thus the house form that protects from the climate must at the same time exploit it. What appears to be simple surface decoration, random fenestration, or ornamentation, is in fact strategic moderation of these daily climatic extremes.

\subsection{Responding aspects of house forms}

The homes are predominantly oriented with exterior spaces to the south. The courtyard serves as a buffer space that protects the building from wind and sun. Activities of daily living that warrant interaction with the courtyard, for example in the kitchen and frequented storeroom spaces are located towards the south side of the home. The rooms are arranged in a pass-through style from the south entrance to the final north wall, so occupants travel through one space to get to the next. This stacking of program creates a layering of interior volumes and the daylight levels from one to the next are tangibly lower. With this layering of light, the most interior spaces are the most protected from daylight and have the most private use, for example the sleeping spaces and the shrine.

Punctures in the wall also follow this rhythm from south entrance to the back north wall. The penetrations to the exterior, entrances and windows, are open with gauze window coverings. Windows within the interior walls, that seem like relights, are actually also covered with gauze to mitigate the ambient light in the front spaces and dampen the light levels even further in the most interior spaces. The rooms along the north wall, the deepest spaces in the home have little or no openings to the north.

In elevation, there are many examples of purposeful vernacular response to mitigating the direct sun. Traditional looking decorative overhangs are in fact substantial shading devices of the south sun. The exterior penetrations are treated with dark paint around the trim and within the doorway to absorb direct sun. The traditional adobe brick material is white washed and outlined to look like a contemporary building material of white brick. The exterior windows of 
the house are treated on the interior with at least one and maybe two layers of fabric to diffuse the power of the direct sun along the south wall.

There are also examples of vernacular climatic responses to other environmental factors. First, the gate that defines the interior courtyard serves not only as a pen for animals but also acts as a buffer for the exposed house against the harsh western wind. Second, the exterior walls are treated with what superficially appears as decorative vertical waves running the height of each story. Upon further investigation, they prove to be rainwater run-off drainage channels to combat the heavy deluge of water during the rainy season and prevent excessive erosion of the adobe.

We posit that in the vernacular form the historic strategies employed to protect and moderate the climate have created a unique interior light quality that is intrinsically imbedded with cultural meaning. What happens when modern interventions alter that quality of light? If the sun is used for passive solar heat gain, can that be done without dramatically changing the filtered interior light that is evident in the culture?

\section{Methods}

To understand these questions, the first step of the investigation is to determine appropriate methods to accurately collect current light level information in vernacular spaces. For this project, we tested three distinct approaches: 1) on site daylight level collection, 2) physical daylight models and 3) HDR photography analysis.

Data was collected on site from one randomly selected rural home of moderate means (Figures 1) and from a second that was selected to represent a family of status within another village. Light level data points in the residence were collected using a light meter at work surface level across a 2' x 2' grid. The interior daylight level readings data points were compared with available exterior daylight level conditions. The interior readings were multiplied by a factor of 0.604 , a standard calculation incorporating the typical opacity of glass and the interference of mullions. The findings were then overlaid on top of the housing plans to depict the daylight zones. In addition to the light meter testing, photographic documentation of the spaces captured the perception of the occupant in the space and the relative layers of light. The schematic drawing (Figure 2) depicts the layout of the second floor of a village home. The plan demonstrates the layering of interiors and the relative daylight levels in the first tier of interior space. The shaded areas represent daylight levels in a communal bedroom/living room on the upper level of the house. In this case, the daylight level in the lower left corner (south eastern exposure) is quite high, approaching a daylight factor of 3-4. By comparison, a recommended day light factor for an office work plane is 2 .

By contrast the next drawing (Figure 3) illustrates readings in a second tier space and represents a dramatic drop in light levels from the first tier.

The shaded areas represent daylight levels in the shrine room. All daylight readings in this space are below a daylight factor of 2 . Compared to the 
brightness or the room in front, this space will experientially seem even darker. Typically a shrine room is considered private space for the use of the family. It is opened only to monks who may visit at the invitation of the family for the purpose of spiritual intervention.

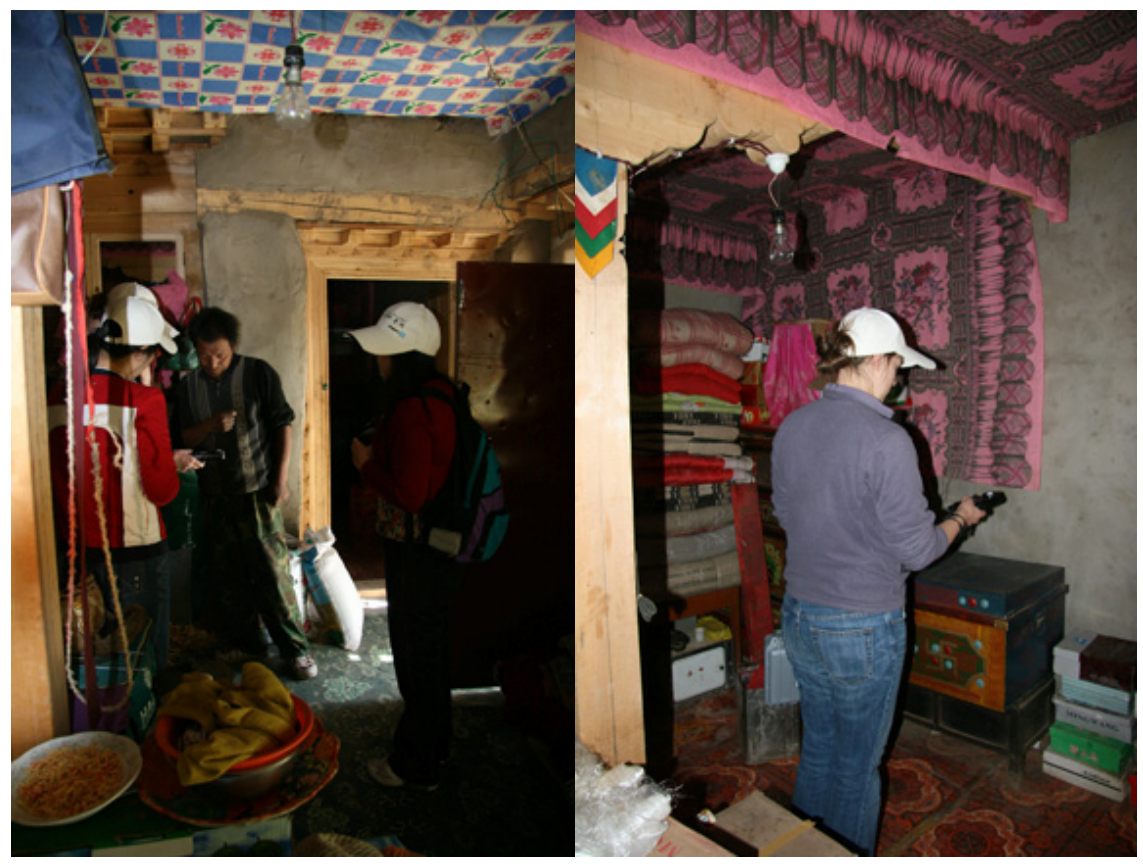

Figure 1: Light levels measured on site by research assistants.

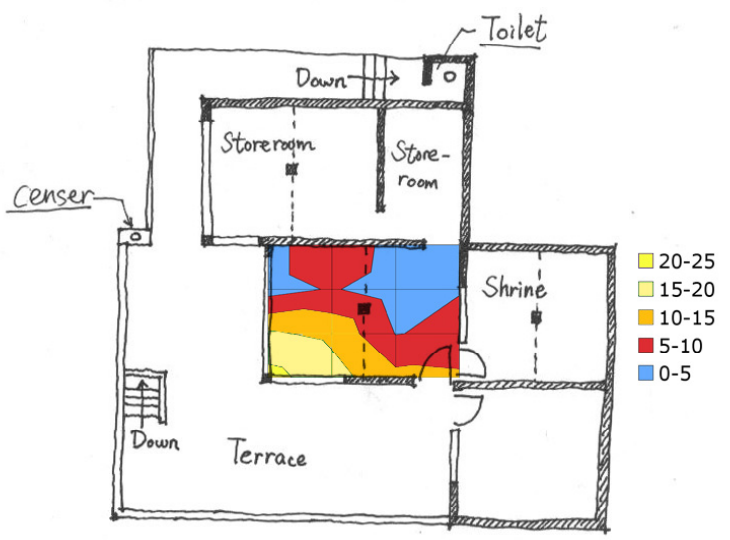

Figure 2: Representative daylight levels in the first tier of space. 


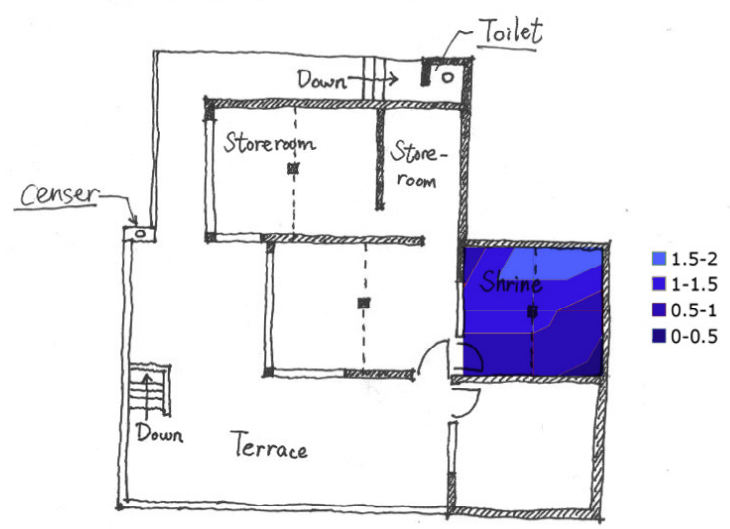

Figure 3: Representative daylight levels in the second tier.

The second method tested was to create scale models of the house in order for the daylight levels to be analyzed in a skybox. The skybox is a mirror-box artificial sky that meets the "International Overcast Sky" standard of being three times brighter at the zenith than it is as the horizon. There are two methods of testing in the skybox: photocell measurement readings and photography. The photocells measure the daylight levels within the space. The photocell readings are then divided by the exterior available daylight to find the Daylight Factor (percentage of available daylight in the space). To record the daylight levels, a control cell is placed above the model to absorb the exterior available light. The remaining cells are then placed within the model and the readings provide a measure of the daylight performance of the space.

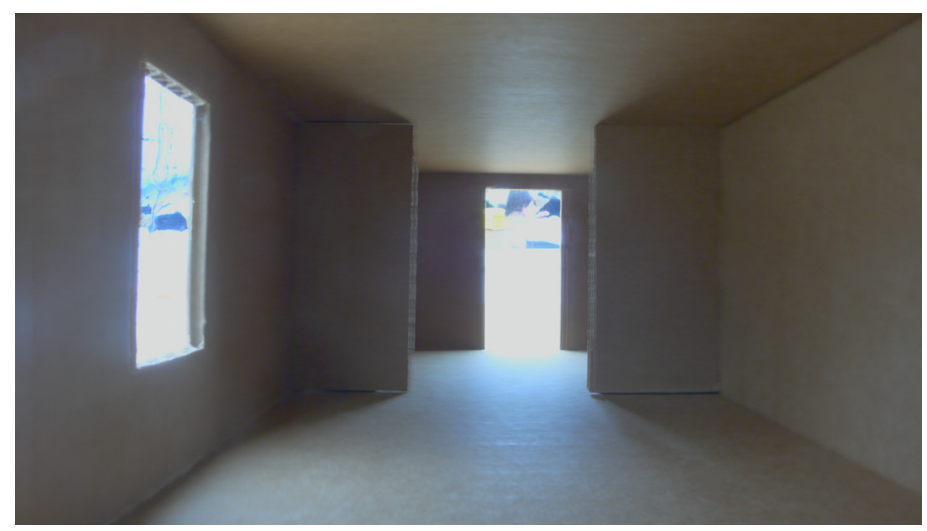

Figure 4: This is the HDR image of the kitchen located in the lower level off the courtyard looking south. The window is in a second tier dining space. 
Finally the models were also photographed using HDR technology to capture all available light levels. HDR stands for high dynamic range imaging. In this case, it applies to a set of tonal analysis that allows for a greater range of exposures than just one photograph alone. HDR is used to capture the total range of levels that exist in the space, from brightest daylight to the darkest shadows. The photographer takes a range of exposures and then inputs them into a software program (Photosphere or Photoshop) to analyze for perception and daylight levels present as well as surface luminance.

The HDR images were also outputted in false colour to depict daylight hotspots in each room as well as the diffusion of light across the space. The colours represent a spectrum of daylight factors from 0 to 2. (Figure 5)

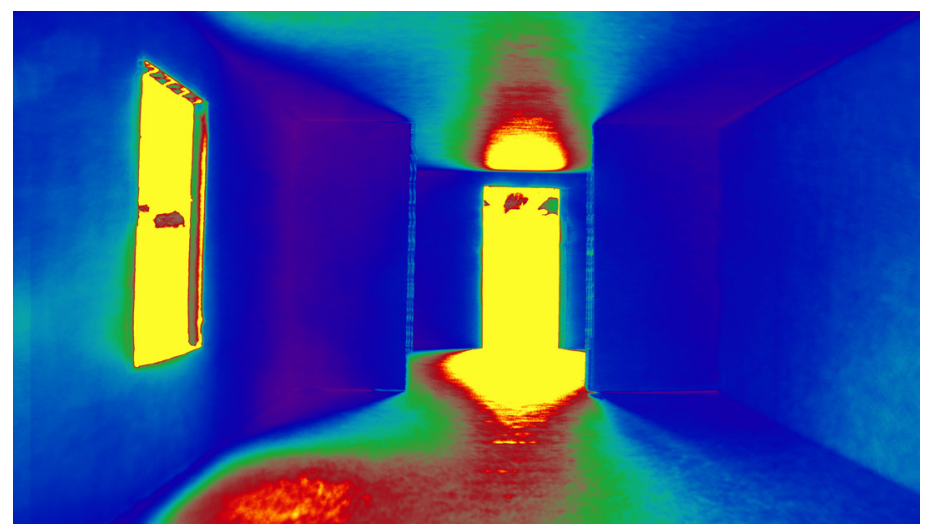

Figure 5: This image is a false colour rendering of the daylight levels throughout the space. There is an obvious hotspot at the door and another small one pooling below the east-facing window. The corners of the space and the partition wall are relatively dark.

\section{Findings}

It appears that the interiors are dark for a reason. The rural Tibetan is trying to escape from the sun. The data demonstrate that there is a deliberate modulation of interior light in the representative vernacular interiors. Any passive solar interventions, if not thoughtfully developed, will dramatically alter this light quality. In particular the use of daylight as an intervention, either in the form of direct sun or ambient light, seems in direct opposition to the examples of the mitigation of sunlight in the interior home space. Since the very nature of typical passive design strategies is to allow more daylight into the space, a contemporary intervention needs to be thoughtfully placed and controlled to allow for varied levels of interior light. The methods tested are a good starting point for this study.

There appears to be a deliberate choice not to use north light in the interior spaces of the home. The choice not to use north light is in contrast to western and 
sustainable notions that take advantage of it as an abundant source of ambient light, escaping the direct sun penetration problems of the southern direct sun.

What we discover in the vernacular form is that the historic strategies employed to protect and moderate the climate have created a unique interior light quality that is likely imbedded with cultural meaning. In addition to measuring light levels in interior spaces, further probing into these cultural meanings is imperative. For example, Chinese students reported that in their tradition north light is considered "evil" light and they refrain from punching any openings that allow light from this direction into the space. At this stage, research has not uncovered notable evidence of that belief in Tibetan tradition so more investigation is necessary to understand the lack of north light observed in the home.

The intention of the GARC project in Tibet is to demonstrate good practices through the design and construction of a contemporary rural Tibetan home. It is through "market" transformation that Dr. Liu hopes to influence how villagers build future rural homes. The problem lies most inherently with interventions that focus on sustainable strategies, for example, green houses, skylights, or daylight monitors. These adaptations tend to flood direct sun into interior spaces. While the energy goals may be successful, what will be lost when the increases in light levels significantly change the nature of the vernacular Tibetan interior? It seems paramount that to be true to the traditional atmosphere of the interior, any passive design intervention will need to understand the current daylight levels and their cultural relevance and balance them with the thoughtful introduction of daylight into the interior spaces.

\section{Acknowledgements}

The authors wish to acknowledge the contribution of research team assistants Stacey DeKoekkoek, and, Jacklin Kingen of Washington State University and He Quan, of Xian University of Architecture and Technology as well as our colleague Dr. David Wang, Professor of Architecture, Washington State University.

\section{References}

[1] Frampton, K., "Towards a Critical Regionalism: Six Points for an Architecture of Resistance," in H. Foster, ed., Postmodern Culture, 1983.

[2] Frampton, K., Critical regionalism: Modern Architecture and Identity in Modern Architecture: a critical history. 1992.

[3] Ibelings, H. Supermodernism: Architecture in the Age of Globalization, 1998.

[4] Wang, W. Sustainability is a Cultural Problem. Harvard Design Magazine 18:3. 2003

[5] Liu J., D. Wang, and L. Yang, An Instance of Critical Regionalism: New Yaodong Dwellings in North-Central China. Field Report TDSR 13 (2):8. 2002. 
[6] Hu, X., Contemporary Regionalism in Chinese Architecture: A Perspective Inspired By K. Frampton's Critical Regionalism (From 1980 To The Present) unpublished dissertation, Washington State University, 2004.

[7] Frampton, K., Critical regionalism: Modern architecture and Identity in Modern architecture: a critical history, 1992.

[8] Liu J., D. Wang, and L. Yang, An Instance of Critical Regionalism: New Yaodong Dwellings in North-Central China. Field Report TDSR 13 (2):8, 2002.

[9] Dincyurek, M. \& O. Oktay, An Investigation on Sustainability Indicators of Vernacular Environments: the Case of Cyprus. Ecosystems and Sustainable Development VI: 10, 2007.

[10] Rasulo, M., Vernacular architecture related to the climate in the Mediterranean basin: a lesson we should learn. International Journal for Housing and Its Applications 27 (3): 11, 2003.

[11] Fathy, H., Natural Energy and Vernacular Architecture, 1986. 